\title{
Commentary \\ Do early premalignant changes in normal breast epithelial cells predict cancer development?
}

\author{
Robert B Clarke ${ }^{1}$ and Nigel J Bundred ${ }^{2}$
}

${ }^{1}$ CR-UK Department of Medical Oncology, University of Manchester, Christie Hospital NHS Trust, Manchester, UK

${ }^{2}$ Academic Department of Surgery, University Hospital of South Manchester, Manchester, UK

Corresponding author: Nigel J Bundred, bundredn@man.ac.uk

Published: 19 November 2004

Breast Cancer Res 2005, 7:18-20 (DOI 10.1186/bcr967)

(c) 2004 BioMed Central Ltd

\begin{abstract}
A recent report suggests that, in an in vitro model of premalignant breast cells (vHMECs), silencing of INK4A gene is accompanied by over-expression of cyclo-oxygenase (COX)-2. This suggests that COX-2 over-expression may be an early event in breast cancer aetiology permitting clones within the normal epithelium to evade apoptosis, to increase their numbers and perhaps acquire further changes that promote the formation of hyperplasias, and eventually carcinomas. While COX-2 expression in normal breast epithelium in vivo has not been proven to be linked to an increased risk of breast cancer, its over-expression in the premalignant model in vitro does provide preliminary evidence that COX-2 inhibition may be a useful chemoprevention strategy.
\end{abstract}

Keywords: apoptosis, breast cancer prevention, cyclo-oxygenase-2, normal breast, premalignant

\section{Introduction}

The aetiology of breast cancer is complex but involves selection of variant cells that develop a growth advantage over and above that of the surrounding normal epithelium. The growth advantage must be a combination of increased proliferation and decreased apoptosis to allow cell survival. Comparison of normal breast tissue around cancer with breast reduction derived epithelium [1] indicated that it is mainly decreased apoptosis rather than increased proliferation that is seen in the normal epithelium in malignant breasts. Bypassing senescence and inhibiting apoptosis permits the accumulation of genomic alterations that push a cell toward a malignant phenotype.

A recent report from Crawford and coworkers [2] compared genes expressed in normal and variant human mammary epithelial cells (HMECs). It identified that, as well as silencing the INK4a gene through promoter methylation, the variant cells over-express cyclooxygenase (COX)-2.

\section{Variant human mammary epithelial cells}

Primary culture of breast tissue from normal women yields HMECs, which senesce after 10-15 population doublings in culture. However, a subpopulation termed variant HMECs are capable of proliferating for an additional 30-50 generations, and reach a plateau of high proliferation and high apoptosis termed agonescence in which the cell population does not increase but sustains itself.

Nearly $100 \%$ of these variant HMECs exhibit telomeric dysfunction and chromosomal defects as they approach agonescence. Many of these defects are similar to those seen in the earliest lesions of breast malignancy, and Crawford and coworkers have already described this variant HMEC population to contain cells with hypermethylated INK4a promoter sequences, which leads to loss of $\mathrm{p} 16^{\mathrm{INK} 4 \mathrm{~A}}$ protein and allows increased cell cycling through cyclin $D_{1}$. The variant HMECs also overexpress the COX-2 protein. 
One limitation in relating variant HMECs to premalignant lesions in vivo is that there is no cell purification step during isolation of HMECs and it is well recognized that this leads to mixed populations of myoepithelial and luminal cells. It is therefore possible that some variant HMECs in vitro are myoepithelial cells and thus they may be unrelated to the luminal cells that comprise most premalignant lesions in vivo. Second, there is no proof that the p16 promoter-methylated cells observed in the breast in vivo are the cells of origin of variant HMECs in culture. Paradoxically, Crawford and coworkers [2] reported that methylation of the p16 promoter was found in only three out of 10 breast samples examined, yet variant HMECs can be cultured from all reduction mammoplasty samples.

\section{Cyclo-oxygenase-2 and breast cancer}

COX-2 is an inducible enzyme that is responsible for the conversion of arachidonic acid to prostaglandins (including prostaglandin $\mathrm{E}_{2}$ and thromboxane) and leading to inflammatory responses in tissues. Transgenic mice engineered to over-express COX-2 have increased development of breast cancer and their breast epithelial cells show reduced apoptosis [3]. Expression of COX-2 is common, with over $80 \%$ of ductal carcinoma in situ and $40 \%$ of invasive breast cancers having the protein. Human breast tumours that are COX-2 positive have high grade, proliferation and oestrogen receptor (ER)-negative status, and are associated with shorter time to recurrence and death [4]. COX-2 over-expression in epithelial cells leads to increased prostaglandin $E_{2}$ secretion and increased matrix metalloproteinase (MMP)-9 release [5]. MMP-9 activity shears cell-bound transforming growth factor- $\alpha$, which transactivates the epidermal growth factor receptor, and epidermal growth factor receptor/c-erbB2 heterodimers, leading to a positive feedback loop in which cells exhibit increased proliferation and reduced apoptosis.

COX-2 positive cells show increased aromatase activity due to the release of prostaglandins, increasing aromatase in surrounding stroma and epithelium, leading to synthesis of oestrogens in the microenvironment around COX-2 over-expressing cells [6]. It appears, however, that it is largely ER-positive breast cancer development that is inhibited by nonsteroidal anti-inflammatory drugs [7]. Increased aromatase activity promotes the growth of ERpositive breast cells, and this is of particular relevance to postmenopausal breast cancer, in which systemic oestrogens are low. Recent epidemiological studies have indicated that there is a reduced incidence of breast cancer in women taking aspirin or other nonsteroidal antiinflammatory drugs (that inhibit COX-2).

\section{Invasive events in normal breast epithelium leading to cancer diagnosis}

The report that COX-2 over-expression is an important early event in the aetiology of breast cancer is very important [2]. COX-2 over-expression would potentially permit clones within the normal epithelium to evade apoptosis, increase their number and eventually occupy luminal spaces where cells would normally undergo anoikis. In normal breast epithelium expressing COX-2, Boland and coworkers [8] showed higher proliferation. COX-2 is a strong candidate for a gene that is intrinsically involved in this process and small molecule inhibitors are readily available. It is not yet clear whether COX-2 or hypermethylation of the INK4a promoter is the first step that allows cells to progress to cancer. COX-2 expression is induced both by the RAS/mitogen-activated protein kinase signalling pathway and by inflammatory stimuli, including carcinogens that increase tumour necrosis factor-induced nuclear factor- $\mathrm{\kappa B}$ activation. Increased expression of cyclin $D_{1}$, COX-2, MMP-9 and several inhibitors of apoptosis proteins (including survivin and IAP1) is often seen with nuclear factor- $\kappa B$ stimulus. These changes can be reversed by RAS farnesyl transferase inhibitors, which induce apoptosis and inhibit angiogenesis. It may be that all of these observed changes relate fundamentally to the underlying carcinogenic stimuli that these breasts are subject to, such as tobacco smoke, chemicals, or radiation.

\section{Conclusion}

At present, the concept that variant HMECs are a precursor cell for either atypical lesions, in situ disease, or even cancer is unproven, and neither have Crawford and coworkers [2] shown that women with COX-2 expression in the majority of epithelial cells in the breast have a subsequently increased risk for breast cancer. These are both fundamental to their argument that such changes promote a premalignant programme. Such evidence will be necessary if we are to pursue a programme investigating COX-2 inhibition as chemoprevention for premenopausal breast cancer. Chemoprevention studies take years to come to fruition. Therefore, further 'in vitro' or 'in vivo' laboratory studies of agents such as celecoxib, a selective COX-2 inhibitor that can inhibit cancer development in mouse models of mammary cancer including the CerbB2 transgenic mouse [9], now need to be backed up with short-term clinical trials. These should test the effects of COX-2 inhibition on the normal breast, particularly whether COX-2 expression is switched off by treatment and whether switch-off leads to increased apoptosis in the normal epithelium.

In addition, studies of normal breast biopsies in women who subsequently went on to develop breast cancer will be important in determining whether COX-2-related changes occurred in these women but not in a population in which cancer did not develop after biopsy. Further clarification of the nature of variant HMEC cells and how they relate to stem cells will also be important. The recent recognition of stem cells within the human breast 
indicates that it may often be damage to these stem cells that is fundamental to the development of cancer. Evidence of the same abnormalities in stem cells from breasts that subsequently develop cancer would also be persuasive. Current chemoprevention strategies have used anti-oestrogens such as tamoxifen, raloxifene, or aromatase inhibitors to inhibit breast proliferation that occurs via an ER-dependent mechanism. These studies only prevent ER-positive breast cancer, but agents that increase apoptosis such as the COX-2 inhibitors will potentially inhibit both ER-positive and ER-negative breast cancer with minimal toxicity. A greater understanding of how to increase apoptosis in the breast may well be the missing piece in the puzzle of how to prevent breast cancer development.

\section{Competing interests}

The author(s) declare that they have no competing interests.

\section{References}

1. Allan DJ, Howell A, Roberts SA, Williams GT, Watson RJ, Coyne JD, Clarke RB, Laidlaw IJ, Potten CS: Reduction in apoptosis relative to mitosis in histologically normal epithelium accompanies fibrocystic change and carcinoma of the premenopausal human breast. J Pathol 1992, 167:25-32.

2. Crawford YG, Gauthier ML, Joubel A, Mantei K, Kozakiewicz K, Afshari CA, Tlsty TD: Histologically normal human mammary epithelia with silenced p16(INK4a) overexpress COX-2, promoting a premalignant program. Cancer Cell 2004, 5:263-273.

3. Liu CH, Chang SH, Narko K, Trifan OC, Wu MT, Smith E, Haudenschild $\mathrm{C}$, Lane TF, Hla T: Overexpression of cyclooxygenase-2 is sufficient to induce tumorigenesis in transgenic mice. J Biol Chem 2001, 276:18563-18569.

4. Ristimaki A, Sivula A, Lundin J, Lundin M, Salminen T, Haglund C, Joensuu $\mathrm{H}$, Isola J: Prognostic significance of elevated cyclooxygenase-2 expression in breast cancer. Cancer Res 2002, 62:632-635.

5. Pai R, Soreghan B, Szabo IL, Pavelka M, Baatar D, Tarnawski AS: Prostaglandin E2 transactivates EGF receptor: a novel mechanism for promoting colon cancer growth and gastrointestinal hypertrophy. Nat Med 2002, 8:289-293.

6. Brueggemeier RW, Quinn AL, Parrett ML, Joarder FS, Harris RE, Robertson FM: Correlation of aromatase and cyclooxygenase gene expression in human breast cancer specimens. Cancer Lett 1999, 140:27-35.

7. Terry MB, Gammon MD, Zhang FF, Tawfik H, Teitelbaum SL, Britton JA, Subbaramaiah K, Dannenberg AJ, Neugut Al: Association of frequency and duration of aspirin use and hormone receptor status with breast cancer risk. JAMA 2004, 291: 2433-2440.

8. Boland GP, Butt IS, Prasad R, Knox WF, Bundred NJ: COX-2 expression is associated with an aggressive phenotype in DCIS. Br J Cancer 2004, 26:423-429.

9. Howe LR, Subbaramaiah K, Patel J, Masferrer JL, Deora A, Hudis C, Thaler HT, Muller WJ, Du B, Brown AM, et al:: Celecoxib, a selective cyclooxygenase 2 inhibitor, protects against human epidermal growth factor receptor 2 (HER-2)/neu-induced breast cancer. Cancer Res 2002, 62:5405-5407. 